Short Communication

\title{
The role of the written script in shaping mirror-image discrimination: Evidence from illiterate, Tamil literate, and Tamil-Latin-alphabet bi-literate adults
}

\author{
Tânia Fernandes ${ }^{\mathrm{a}, *}$, Mrudula Arunkumar ${ }^{\mathrm{b}}$, Falk Huettig ${ }^{\mathrm{b}, \mathrm{c}}$ \\ ${ }^{\text {a }}$ Faculdade de Psicologia, Universidade de Lisboa, Portugal \\ ${ }^{\mathrm{b}}$ Max Planck Institute for Psycholinguistics, Nijmegen, the Netherlands \\ c Centre for Language Studies, Radboud University, Nijmegen, the Netherlands
}

\section{A R T I C L E I N F O}

\section{Keywords:}

Mirror images

Mirror invariance

Mirror-image discrimination

Orientation processing

Literacy acquisition

Tamil

\begin{abstract}
A B S T R A C T
Learning a script with mirrored graphs (e.g., $\mathrm{d} \neq \mathrm{b}$ ) requires overcoming the evolutionary-old perceptual tendency to process mirror images as equivalent. Thus, breaking mirror invariance offers an important tool for understanding cultural re-shaping of evolutionarily ancient cognitive mechanisms. Here we investigated the role of script (i.e., presence vs. absence of mirrored graphs: Latin alphabet vs. Tamil) by revisiting mirror-image processing by illiterate, Tamil monoliterate, and Tamil-Latin-alphabet bi-literate adults. Participants performed two same-different tasks (one orientation-based, another shape-based) on Latin-alphabet letters. Tamil monoliterate were significantly better than illiterate and showed good explicit mirror-image discrimination. However, only biliterate adults fully broke mirror invariance: slower shape-based judgments for mirrored than identical pairs and reduced disadvantage in orientation-based over shape-based judgments of mirrored pairs. These findings suggest learning a script with mirrored graphs is the strongest force for breaking mirror invariance.
\end{abstract}

\section{Introduction}

When writing was invented $\sim 5500$ years ago (a glimpse in evolutionary time), no one could imagine its impact on the human brain and mind. Learning to read leads to nontrivial changes in neural networks (Carreiras et al., 2009; Dehaene-Lambertz, Monzalvo, \& Dehaene, 2018; Dehaene et al., 2010; Hervais-Adelman et al., 2019), especially in the ventral visual pathway dedicated to object recognition (Dehaene, Cohen, Morais, \& Kolinsky, 2015).

Literacy-related processing of mirror images (i.e., $180^{\circ}$ reflection around image axes; e.g., d-b) is perplexing because it requires the 'unlearning ${ }^{1}$ of evolutionary-old and cross-species mechanism of mirror invariance, i.e., tendency to process mirror images as equivalent, possibly consequence of convergent evolution by similar ecological demands. Natural objects are often symmetric; hence, mirror-image discrimination would delay recognition (Bornstein, Gross, \& Wolf, 1978; Corballis, 2018; Dehaene et al., 2015; Lachmann \& van Leeuwen, 2008,
2014; Logothetis, Pauls, \& Poggio, 1995). Investigating it is critical for understanding cultural re-shaping of evolutionarily-inherited cognitive mechanisms.

Mirror invariance is a robust perceptual phenomenon, mostly in people without reading skills: preliterate children and illiterate adults (e. g., Fernandes, Coelho, Lima, \& Castro, 2018; Gibson, Pick, Osser, \& Gibson, 1962; Kolinsky et al., 2011). It is not about post-perceptual or memory processes (Corballis, 2018): For non-readers, mirror-image discrimination is hard (across-task: e.g., visual search, same-different matching, card sorting; Fernandes et al., 2018; Fernandes, Leite, \& Kolinsky, 2016; Kolinsky et al., 2011), more in simultaneous than in sequential presentation (Kolinsky et al., 2011; Kolinsky \& Verhaeghe, 2017). It is neither because orientation is a hard dimension: Non-readers can discriminate plane rotations (i.e., rotation in the image-plane of, e.g., $180^{\circ}$, $\mathrm{u}$ and $\mathrm{n} ; \mathbf{9 0}^{\circ}, \mathrm{N}$ and Z: Bornstein et al., 1978; Fernandes \& Kolinsky, 2013; Fernandes et al., 2016; Kolinsky et al., 2011), for which they are as able to attend to orientation (in orientation-based tasks,

\footnotetext{
* Corresponding author at: Faculdade de Psicologia, Universidade de Lisboa, Alameda da Universidade, 1649-013 Lisboa, Portugal.

E-mail address: tpfernandes@psicologia.ulisboa.pt (T. Fernandes).

${ }^{1}$ Whether mirror invariance is unlearned (e.g., Dehaene et al., 2010; Pegado, Nakamura, Cohen, \& Dehaene, 2011; Pegado, Nakamura, \& Hannagan, 2014), suppressed (e.g., Lachmann \& van Leeuwen, 2008), or inhibited (e.g., Ahr, Houdé, \& Borst, 2016; Duñabeitia, Molinaro, \& Carreiras, 2011; Perea et al., 2011) in the course of literacy acquisition has been intensively debated and is still unclear.
} 
where plane-rotations must be classified as different) as to shape (in shape-based tasks, where they must be classified as same). Plane rotations, but not mirror images, are discriminated by the ventral pathway (e.g., Logothetis et al., 1995; Martinaud et al., 2016).

Learning to read entails training in a script with a specific writing/ reading direction and graphs ${ }^{2}$ have a specific orientation, part of their identity (Morin, 2018). Here rests one key difference between nonlinguistic objects and letters (Gibson et al., 1962): a chair is a chair even if upside-down, but $R$ is different from $s$ (the latter is not a Latin-alphabet letter) and $d$ is different from $b$. In scripts with reversible letters (i.e., which differ in orientation contrast: plane-rotation, e.g., $\mathrm{u}$ and $\mathrm{n}$, or mirror-image, e.g., b and d), mirror-image discrimination is mandatory (e.g., Perea, Moret-Tatay, \& Panadero, 2011). Once acquired, it generalizes to nonreversible letters (e.g., R) and, intriguingly, to nonlinguistic objects (e.g., pictures/photographs of tools; geometric, letter-like shapes) from early on in reading development, regardless of schooling or age of literacy acquisition (de Heering, Collignon, \& Kolinsky, 2018; Fernandes et al., 2018; Fernandes \& Kolinsky, 2013). Learning a script with mirrored graphs may be critical: only readers of a script without (Tamil, the Indian script) who were bi-literate, that is, readers of another natural script with mirrored graphs (Latin alphabet) showed good explicit mirror-discrimination, in a part-whole task, where "no" response was required if the part was a mirror image of a component of the whole (Danziger \& Pederson, 1998; Pederson, 2003).

This conclusion might, however, be premature, considering the script properties and literacy-related consequences in visual processing. We thus revisited mirror-image processing by illiterate, Tamil monoliterate, and Tamil-Latin-alphabet bi-literate adults to investigate the impact of literacy and script in shaping mirror-image processing, overcoming the caveats on task, material, and literacy-classification of previous research (Danziger \& Pederson, 1998; Pederson, 2003).

Regarding the script, statistical learning and handwriting assist mirror-image discrimination (e.g., Fischer, 2017; Longcamp et al., 2008; Treiman, Gordon, Boada, Peterson, \& Pennington, 2014), for which multi-system (visual, phonological, and motor) interplay is critical (Pegado, Nakamura, \& Hannagan, 2014). Therefore, as Tamil has more graphs and is visually more complex than Latin alphabet (Chang, Chen, \& Perfetti, 2018), is written/read from left-to-right, and each akshara ${ }^{3}$ has a specific orientation (Nag \& Narayanan, 2019; Steever, 1996), Tamil literate adults (illiterate in other scripts) could show sensitivity to mirror-image differences. At least numerically, Tamil literate were better than illiterate on deciding that a mirrored part did not belong to the whole (Pederson, 2003; accuracy: $59 \%$ by 28 Tamil literate; $35 \%$ by 4 illiterate; $98 \%$ by 16 bi-literate). However, post-perceptual processes taint this task and literacy is not a reliable predictor: ex-illiterate (who acquired literacy in adulthood) are as poor as non-readers (Kolinsky, Morais, \& Brito-Mendes, 1990; Kolinsky, Morais, Content, \& Cary, 1987). More important, literacy-related consequences are not confined to explicit mirror-discrimination tasks. As spillover effect, mirror-image discrimination becomes compulsory, even if task-irrelevant. In a shapebased task, readers show a mirror cost: they are slower on same mirrored

\footnotetext{
${ }^{2}$ Graphs are two-dimensional shapes that participate alone or in combination in coding a linguistic unit (e.g., phoneme, syllable). They differ from other visual categories as natural scenes or faces but are similar to line drawings (both share general two-dimensional properties) from which they become differentiated early on in literacy acquisition (Chang et al., 2018). The term graph applies to visual symbols of any script, and hence, is preferred to the term letter (specific to alphabets).

3 Aksharas represent syllables and are subsyllabic graphs used in alphasyllabic Indic scripts as Tamil (a Brahmi-descendent script comprising 247 aksharas); they represent the onset, or onset plus nucleus, or nucleus alone, but not phonemes (for details, see, Nag \& Narayanan, 2019; Ramanujan \& Weekes, 2019; Steever, 1996). In Tamil, each consonant graph includes the inherent vowel /e/, and vowels are represented alone or as diacritic of consonants (e.g., இ, ரி and லి: /i/ initial, and as diacritic in /ri/ and /li/, respectively).
}

(e.g., d-b) than identical (d-d) trials (de Heering \& Kolinsky, 2019; Fernandes et al., 2016; Kolinsky \& Fernandes, 2014; Pegado et al., 2014). Therefore, to fully assess mirror-discrimination, we adopted two same-different matching tasks: one shape-based (where mirrorinvariance assists successful performance and a mirror cost reflects automatic mirror-discrimination); another orientation-based (explicit orientation-discrimination, including mirror-discrimination).

Note that breaking of mirror invariance (that is, mirror-image discrimination even when deleterious for successful performance) is first found for letters. Preschoolers (from a Latin-alphabet monoliterate background) show a mirror cost only on Latin-alphabet letters (regardless of letters being reversible or nonreversible) but still show a disadvantage on orientation-based over shape-based judgments of mirrored pairs, no longer found in readers (Fernandes et al., 2016; Fernandes \& Leite, 2017). Therefore, instead of multicomponent shapes (Danziger \& Pederson, 1998; Pederson, 2003), we used Latin-alphabet letters to increase the power of detecting mirror costs in shape-based judgments. ${ }^{4}$ For bi-literate, letters are objects of expertise, for which mirrordiscrimination is the strongest (e.g., de Heering \& Kolinsky, 2019). For Tamil monoliterate, letters are familiar and close to aksharas, whose features' proximity could lead to maximal effects related with Latinalphabet knowledge (Fernandes et al., 2016; Hannagan, Amedi, Cohen, Dehaene-Lambertz, \& Dehaene, 2015).

To ensure the effects of literacy and script were specific to mirror images, four trial-types were used in both tasks: fully-different (i.e., letters with different shape and orientation: e.g., b-u), identical (i.e., exact matches; e.g., b-b), ${ }^{5}$ and mirror-image (e.g., b-d) and plane-rotation trials (e.g., b-q; cf. Fernandes et al., 2016). The latter two are critical in between-group comparisons because both are orientation-contrasts with incongruent shape and orientation, but literacy mostly affects mirror-image processing (Fernandes \& Kolinsky, 2013; Kolinsky et al., 2011). We thus predicted a Group x Task x Trial-type interaction and computed the between-task difference for mirrored and rotated trials. This index results from a direct comparison at the individual level (i.e., whether one is able to attend to one dimension over another on incongruent stimuli) rather than from an indirect comparison using different baselines (like the performance drop in mirrored relative to different trials on orientation-based judgments and the mirror cost relative to identical trials on shape-based judgments). We thus examined whether Tamil monoliterate overcome the disadvantage in orientation-based over shape-based judgments of mirrored pairs. Finally, instead of coding literacy dichotomously based on self-report (Danziger \& Pederson, 1998) or recognition of one highly-familiar word and simple sentences (Pederson, 2003), we tested if literacy-related skills were correlated with these indexes.

\section{Method}

\subsection{Participants}

The ethical board of ARUWE, an NGO in Chennai, approved this study, following international guidelines, including the Declaration of

\footnotetext{
${ }^{4}$ These letters are of course not graphs of Tamil but are quite frequent in India, a multilingual and multiliterate country (with 22 major languages, written in 13 different scripts). Latin-alphabet letters are often found in outdoors and in national newspapers with major circulation (e.g., Times of India, Hindustan Times).

5 The same rational underlies fully-different and identical trials. The former have different shape (including their features) and orientation, and hence, require a "different" response in both shape-based and orientation-based tasks, while the later are exact matches with same shape and same orientation, and hence, require a "same" response in both tasks. Therefore, these are the easiest trials and allow ensuring that any difference between groups in mirror-image and/or plane-rotation trials is not due to overall differences in task performance.
} 
Helsinki. Seventy-four Tamil native speakers from similar cultural and residential backgrounds ${ }^{6}$ were paid and participated voluntarily, after they gave informed consent. The groups (based on literacy-related skills; further details, Supplemental material and Table 1) were matched in female/male proportion, $X^{2}(2)=3.72, p=.20$, and age, $F<1: 21$ illiterate, 22 monoliterate, and 31 bi-literate.

\subsection{Material and procedure}

Task, trial-type, and procedure were as in Fernandes et al. (2016), but only letters were used: a, b, e, h, k, m, p, u. ${ }^{7}$ Oral instructions were given with six demo-trials. In computerized trials (controlled by E-Prime 2.0, www.pstnet.com/eprime), sequential letter pairs were presented in two tasks (see Fig. 1), which, in turn, differed only in matching criterion (additional details in Supplemental material). In the shape-based task, participants were asked to decide if the second stimulus (S2) had the same shape (or not) as the first (S1), regardless of orientation: they should respond same on identical, mirror-image, and plane-rotation trials, and different on fully-different trials. In the orientation-based task, they were asked to decide if $\mathrm{S} 2$ was identical (exact match) to S1, otherwise they should respond different (i.e., mirror-image, plane-rotation, and fullydifferent trials).

In each task, after 12 practice trials, participants performed 96 trials (randomized order; shape-based task first: 48 fully-different; 16 identical; 16 mirror-image; 16 plane-rotation; orientation-based task: 48 identical; 16 fully-different; 16 mirror-image; 16 plane-rotation).

Table 1

Profile of the three groups (M and SD).

\begin{tabular}{|c|c|c|c|}
\hline & $\begin{array}{l}\text { Illiterate ( } n \\
=21)\end{array}$ & $\begin{array}{l}\text { Tamil literate } \\
(n=22)\end{array}$ & $\begin{array}{l}\text { Bi-literate }(n \\
=31)\end{array}$ \\
\hline Age (in years) & $\begin{array}{l}36.22(5.79) \\
{[26-49]}\end{array}$ & $\begin{array}{l}36.50(5.57) \\
{[25-45]}\end{array}$ & $\begin{array}{l}36.42(5.86) \\
{[25-50]}\end{array}$ \\
\hline Female:Male proportion & $15: 6$ & $16: 6$ & $16: 15$ \\
\hline Reading fluency ${ }^{\mathrm{a}}$ & $0.09(0.30)$ & $29.23(14.56)$ & 63.16 \\
\hline Tamil words & {$[0-1]$} & [12-62] & $\begin{array}{l}(14.82) \\
{[34-94]}\end{array}$ \\
\hline Tamil pseudowords & $0.00(0.00)$ & $14.91(11.11)$ & $\begin{array}{l}41.68 \\
(13.01)\end{array}$ \\
\hline & 0 & {$[1-40]$} & [14-64] \\
\hline Latin-alphabet words & $\begin{array}{l}(0.00) \\
0\end{array}$ & $\begin{array}{l}0.50(1.30) \\
{[0-4]}\end{array}$ & $\begin{array}{l}44.26 \\
(13.87) \\
{[21-72]}\end{array}$ \\
\hline Latin-alphabet pseudowords & $\begin{array}{l}(0.00) \\
0\end{array}$ & $\begin{array}{l}0.04(0.21) \\
{[0-1]}\end{array}$ & $\begin{array}{l}29.68(9.41) \\
{[7-40]}\end{array}$ \\
\hline $\begin{array}{l}\text { Latin-alphabet letter naming } \\
\text { (26 lowercase letters) }\end{array}$ & $\begin{array}{l}1.76(3.36) \\
{[0-10]}\end{array}$ & $\begin{array}{l}13.82(8.53) \\
{[0-26]}\end{array}$ & $\begin{array}{l}26(0.00) \\
{[26]}\end{array}$ \\
\hline
\end{tabular}

Note. Minimum and maximum are in brackets. No cut-off was applied for participants' inclusion.

a Details on reading tasks are in Supplementary material.

\footnotetext{
${ }^{6}$ There are some inherent limitations on socioeconomic matching when illiterate and literate adults are compared. However, to ensure that the groups were as closely matched as possible, the NGO ARUWE helped us to recruit participants from the same (urban poor) social class from the outskirts of Chennai (the capital city of Tamil Nadu, India). ARUWE aims to provide quality care and social support, and access to education.

7 The present study exclusively used letters (the only material examined) in order to increase the power of detecting a modulation by script on mirror-image processing under the limited time and resources available. Material, E-Prime programs, and data are available at https://osf.io/byqwj/; [database] Fernandes et al. (2019).
}

\section{Results}

In the mixed ANOVA run on Signal Detection Theory d' scores ${ }^{8}$ for same-different designs (cf. differencing model; Macmillan \& Creelman, 2005), with group (illiterate, Tamil literate, bi-literate), task (shapebased, orientation-based), and dimension (identity, mirror, rotation), ${ }^{9}$ the three-way interaction was significant, $F(4,142)=2.55, p=.042, \eta \mathrm{p}^{2}$ $=.067, M S E=0.36 .{ }^{10}$ Analyses on accuracy and RTs were congruent (see Supplemental material).

Similar to previous findings (Fernandes \& Kolinsky, 2013; Kolinsky et al., 2011), groups differed specifically for mirror images, depending on task, $F(2,71)=4.44, p=.015, \eta p^{2}=.111, M S E=0.593$, but not for the other dimensions, including rotations, both $F \mathrm{~s}<1$.

Likewise, in Bayesian analyses ${ }^{11}$ (JASP, Team, 2019; Jeffreys, 1961; Wagenmakers et al., 2018) the model with Group x Task was reliable only for mirror pairs; the interaction received moderate evidence over the model without it $\left(\mathrm{BF}_{10}=2.93\right.$, error: $2.22 \%$; vs. null model: $\mathrm{BF}_{10}>$ 100 , error: $1.52 \%$ ) and was supported by the analysis of effects, $\mathrm{BF}_{\mathrm{incl}}=$ 11.71. In contrast, there was strong support against the interaction for both rotation and identity: $\mathrm{BF}_{\text {excl }}=8.81$ and $=10.64$.

Literacy and learning a script with mirrored graphs had a modulator role only on mirror-image processing. To further test it, while discarding potential alternatives, we focused on the results for mirror and rotation pairs between-tasks, as shape and orientation are incongruent on both. Thus, difficulties in attending to orientation or in task switching would need to hold for both. Yet, they did not (further analyses in Supplemental material).

Fig. 2 shows that illiterate adults had a clear disadvantage on orientation-based over shape-based judgments of mirror pairs, whereas bi-literate had the smallest disadvantage (no difference between-tasks on RTs, see Supplemental material), being quite able to attend to orientation or shape of these pairs. Interestingly, Tamil literate showed good explicit mirror-image discrimination, and significantly better than illiterate, $F(1,71)=5.21, p=.025, \mathrm{BF} 10=2.87$, albeit significantly worse than bi-literate, $F(1,71)=8.63, p=.004$, BF10 $=10.81$. The groups significantly differed on their mirror performance drop (mirror vs. identity pairs) in the orientation-based task, $F(2,71)=4.25, p=.018$, but not on rotation drop, $F<1$. All were as able to discriminate planerotations as identity (illiterate, $F(1,71)=2.40, p=.12$; Tamil literate and bi-literate, both $F s<1$ ). These results suggest literacy (regardless of script) specifically assists explicit mirror-discrimination.

However, learning a script with mirrored graphs seems critical so that spillover effects occur when mirror-discrimination is taskirrelevant. On the one hand, in shape-based judgments, only bi-literate adults did show a mirror cost, but only on RTs, with slower shapebased judgments on mirrored than identical trials, $F(1,71)=5.86, p$

\footnotetext{
${ }^{8}$ D' scores are a bias-free estimate of discriminability, computed over hits (i. e., the proportion of correct responses in different-response trials) and false alarms (i.e., the proportion of incorrect responses in same-response trials), and hence are preferred to accuracy.

${ }^{9}$ A fourth factor (letter type) was not considered in the main analyses but the four-way ANOVAs including it are reported on Supplemental material. In these latter analyses, the results reported here remained significant.

${ }^{10}$ Effect sizes were computed with partial eta squared ( $\eta$ p2) and Cohen d (i.e., the ratio between the difference of the mean between two conditions/groups and the pooled standard deviation; Cohen, 1988). Other significant effects found in the omnibus ANOVA: Group, $F(2,71)=10.28, p<.001, \eta \mathrm{p}^{2}=0.224$, MSE $=5.46$; Task, $F(1,71)=10.83, p=.002, \eta \mathrm{p}^{2}=0.132$, MSE $=1.37$; Dimension, $F(2,142)=29.35, p<.001, \eta p^{2}=0.292$, MSE $=0.36$; Task $\mathrm{x}$ Dimension, $F(2,142)=39.78, p<.001, \eta p^{2}=0.359$, MSE $=0.36$. No other interaction with group was significant (Group x Task, $F<1$; Group x Dimension, $F(4,142)=1.30, p=.27)$.

${ }^{11}$ Bayes factor, $\mathrm{BF}$, was computed with JASP (2019). $\mathrm{BF}_{10} \in[3,10]$ indicates moderate evidence in favor of the alternative hypothesis and BF10 $>10$ indicates strong evidence.
} 


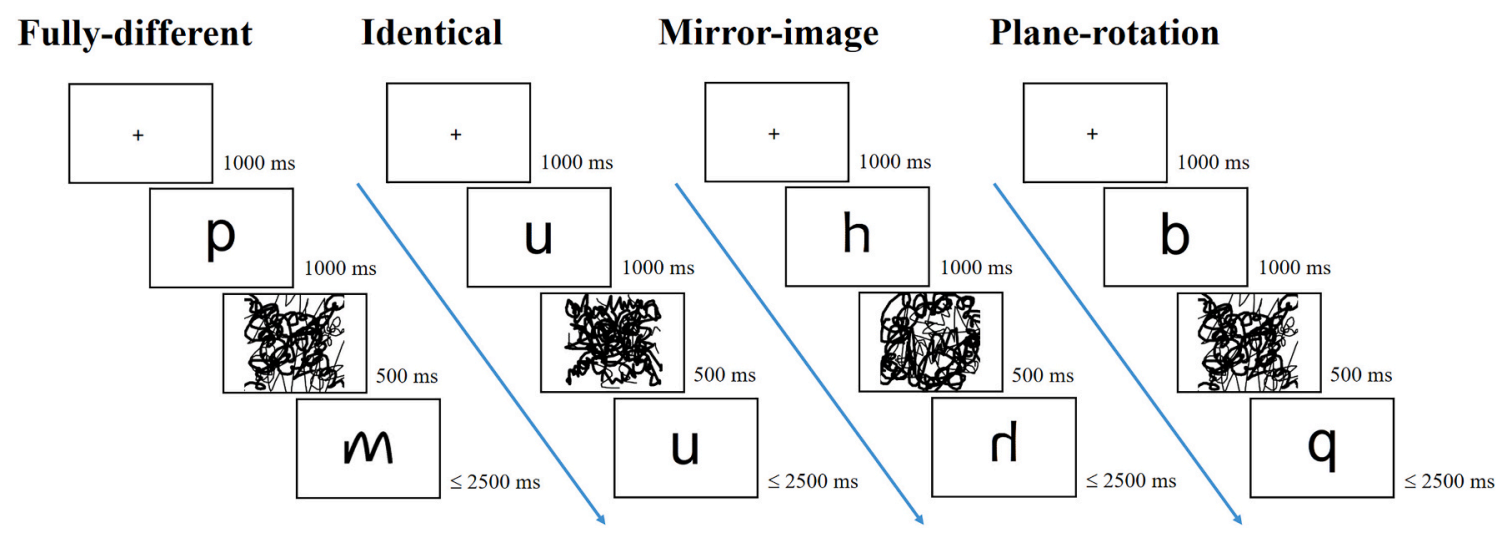

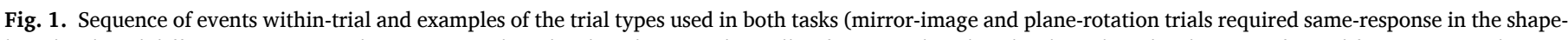

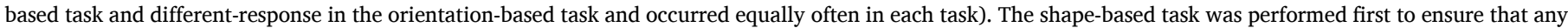

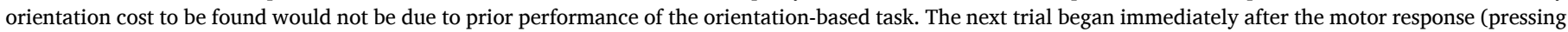

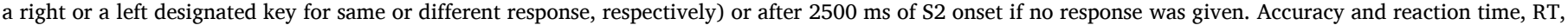
from S2 onset to motor-response onset were collected in each trial with E-Prime 2.0.

Shape-based Task

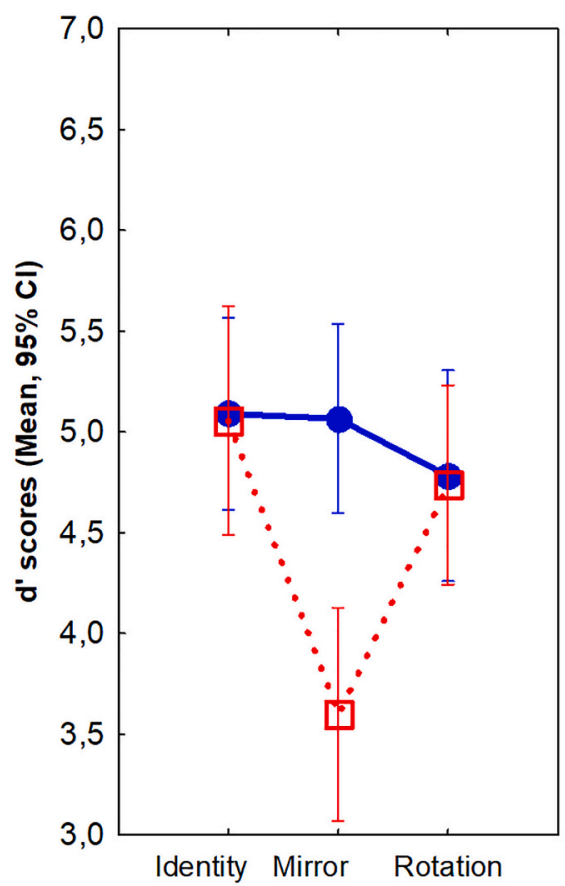

Illiterate

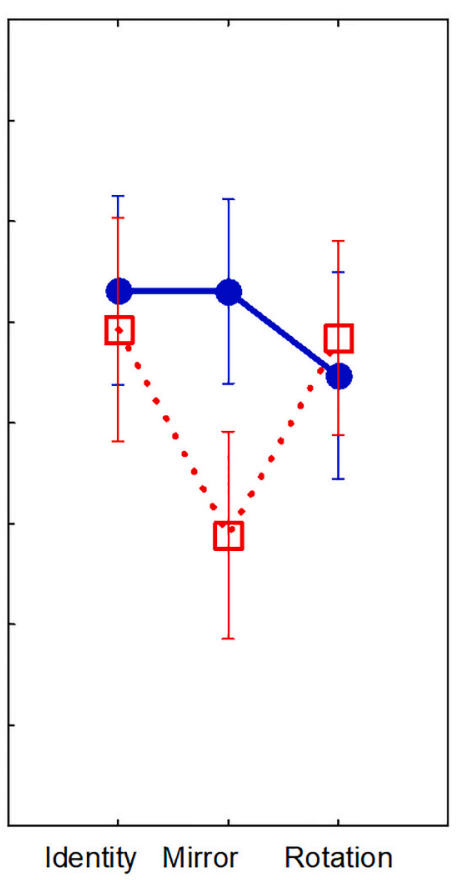

Tamil Literate (Latin alphabet Illiterate)

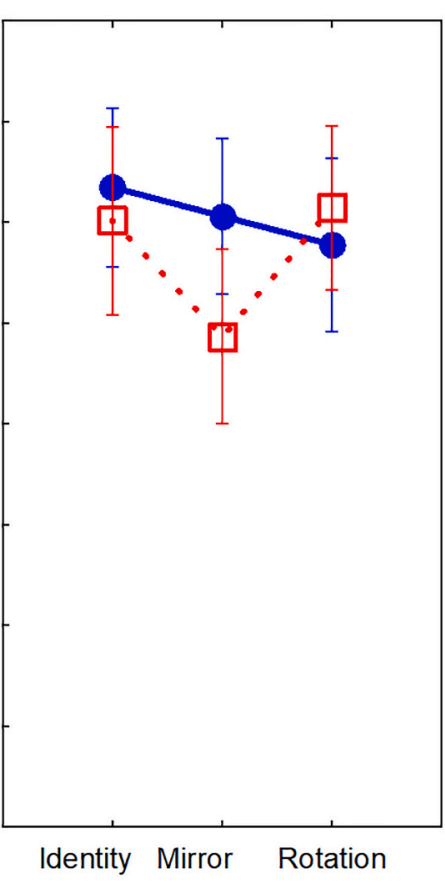

\section{Bi-Literate}

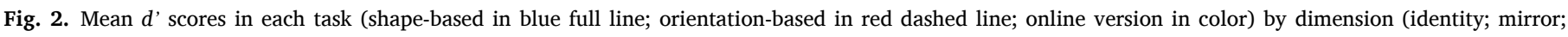

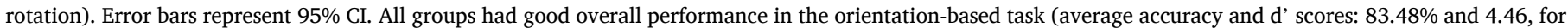

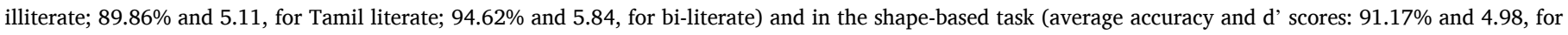

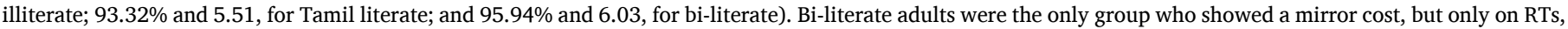

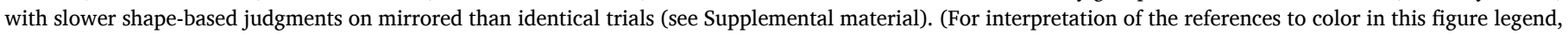
the reader is referred to the web version of this article.) 
$=.018$ (on accuracy, $F<1$, d' scores, $F(1,71)=1.31, p=.25$; see Supplemental material). Neither illiterate or Tamil literate showed mirror costs (on d', accuracy, or RTs, all $p s \geq .10$ ). Yet, all showed rotation costs, all $\mathrm{Fs}(1,71)>5.20$, $p \mathrm{~s}<.025$, of similar magnitude, $\mathrm{F}<$ 1. On the other hand, pairwise comparisons ${ }^{12}$ showed that Tamil literate had a significantly larger disadvantage than bi-literate adults on orientation-based over shape-based judgments for mirror pairs, $t(51)=$ $2.25, p=.01$, Cohen $\mathrm{d}=0.63, \mathrm{BF}-0=4.16$, but not for plane-rotations, $t$ (51) $<1$, BF-0 $=0.28$. The same pattern was found for illiterate vs. biliterate: mirror pairs, $t(50)=2.71, p=.005$, Cohen $\mathrm{d}=0.77$, BF- $0=$ 10.20 ; rotations, $t<1$, BF- $0=0.47$. Therefore, Tamil literate had good explicit mirror-image discrimination abilities but still showed the same disadvantage on orientation-based over shape-based judgments of mirrored pairs as illiterate (both $t(41)<1, p>.50$, BF10 $=0.37$ and $=$ 0.34 , respectively, error $<0.001 \%$ ), and no mirror cost on shape-based judgments.

Correlation analyses reinforced that fully breaking mirror invariance strongly depends on training (or at least on explicit knowledge) in a script with mirrored graphs: The better Latin-alphabet literacy-related skills, the smaller the disadvantage on orientation-based over shapebased judgments (between-task difference on $d$ ' scores) for mirror images, $r(72)=-.36, p<.001$, BF- $0=9.93$, but not rotations, $r(72)=$ $-.06, p=.31, \mathrm{BF}-0=0.21$. Fig. 3 shows this correlation pattern for Tamil-literate adults, for whom this association was only significant with literacy-related skills in Latin-alphabet but not in Tamil. In short: the larger Tamil monoliterate's Latin-alphabet skills, the smaller their disadvantage on orientation-based over shape-based judgments of mirrored pairs.

\section{Discussion}

Our study clarifies the role of the written script in shaping mirrorimage discrimination and provides two original contributions. It shows that, first, explicit mirror-image discrimination depends on learning to read regardless of script, given that readers of a script without mirrored graphs (Tamil monoliterate) show good explicit mirror-image discrimination. Second, automatic mirror-discrimination (when task-irrelevant) depends on learning a script with mirrored graphs: only Tamil-Latin-alphabet bi-literate showed a mirror cost on shape-based judgments. These findings diverge from Pederson (2003), who reported that Tamil monoliterate were as poor as illiterate adults (albeit numerically better) in deciding that a mirrored part did not belong to a whole. By overcoming the caveats on task, material, and literacy classification of Pederson (2003; Danziger \& Pederson, 1998), we found that mirror-image discrimination is necessarily trained when learning to read because any script has a specific writing/reading direction (e.g., left-to-right in Tamil and Latin alphabet) and graphs' orientation is a defining part of their identity (Gibson et al., 1962; Morin, 2018). People are sensitive to visual regularities and through extended practice (including training on writing direction and handwriting) get better at mirror-image discrimination (Chang et al., 2018; Fischer, 2017; Longcamp et al., 2008; Pegado et al., 2014).

An interesting characteristic of the Latin alphabet is that mirrored graphs are reversible letters which, in turn, also include plane-rotation contrasts of $90^{\circ}$ (e.g., $\mathrm{N}$ and $\mathrm{Z}$ ) and $180^{\circ}$ (e.g., $\mathrm{n}$ and $\mathrm{u}, \mathrm{p}$ and d). Note that Latin-alphabet monoliterate children show worse shape-based judgments of reversible than nonreversible letters for both mirrored and rotated pairs, and no influence of letter type on orientation-based judgments (Fernandes et al., 2016). The same result was found here for bi-literate adults (see Supplementary material). Critically, regardless of letter type, Tamil bi-literate differed from illiterate and Tamil

\footnotetext{
${ }^{12}$ Given the a-priori hypotheses (i.e., difference between-groups exclusively for mirror pairs but not for rotations), these pairwise comparisons were conducted with unilateral $t$-tests.
}
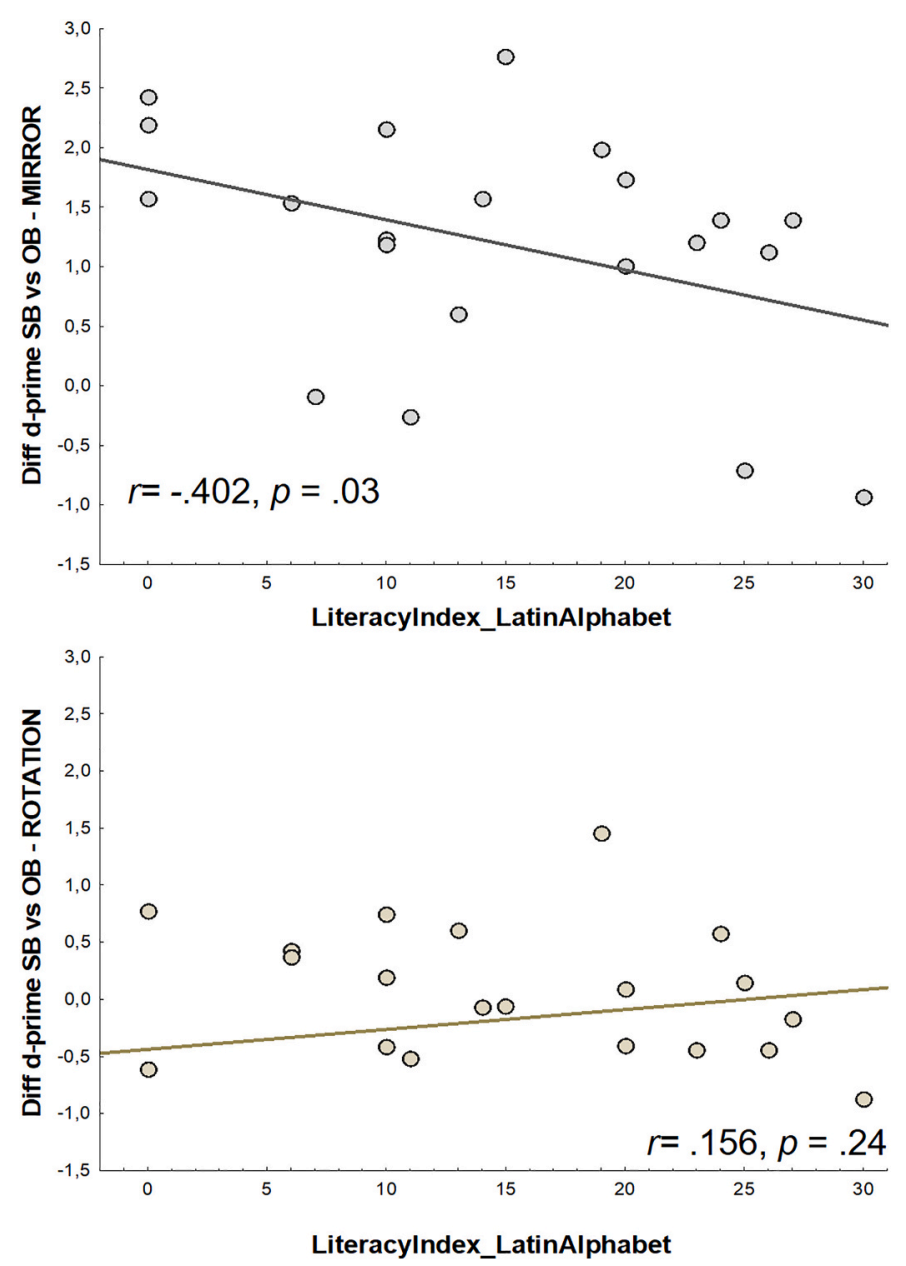

Fig. 3. Scatterplot and correlation coefficients for Tamil literate adults (Latinalphabet illiterate; $n=22$ ) between the literacy index in Latin alphabet (sum score in letter naming and word and pseudoword reading) and the difference on average d' scores between shape-based (SB) and orientation-based (OB) tasks for mirror (top) and rotation (bottom) pairs. The better the Latin-alphabet skills of Tamil monoliterate adults, the smaller the difference on d' scores between tasks for mirror pairs but not for rotation pairs. This correlation was not significant when literacy in Tamil was considered (for mirror and rotation pairs, $r$ $(20)=-0.29$, and $=-0.10, p s>0.18$, BF10 $=0.59$, and $=0.29$, respectively).

monoliterate adults on mirror-image processing only. We note that the differential influence of literacy and script on mirror-image and planerotation contrasts is not because orientation is a hard dimension or difficulties in task-switching. It is neither due to phonological processing (e.g., "saying" the letter name). For reversible letters, plane rotations are also phonologically contrastive (e.g., $d$ and $p ; n$ and $u$ ), and occurred as often as mirrored pairs in our study. Furthermore, phonological processing is not involved on orientation-based letter-matching, even when ISI (interstimulus-interval) between S1 and S2 is as long as $1 \mathrm{~s}$ (Bigsby, 1988; Boles, 1986; Carrasco, Kinchla, \& Figueroa, 1988).

Neither here nor in previous research with children from a Latinalphabet monoliterate background (Fernandes et al., 2016), mirrorimage discrimination was exclusively found for reversible letters. Literacy-related consequences in mirror-image processing occur for both reversible and nonreversible letters (Fernandes et al., 2016; Fernandes \& Leite, 2017). Whether similar results would occur in a script with only mirrored graphs (not rotated ones) would require an artificial script, which poses some challenges, such as deontological issues with preliterate or illiterate participants (whether is acceptable to train nonreaders in artificial, real-life irrelevant, scripts), and transfer effects with readers (whether orthographic-like processing would quickly occur 
for the new script or competition between the native and novel scripts).

We point out that mirror-image discrimination is not specific to the Latin alphabet, literacy, or visual training. Illiterate adults who are lacemakers, and hence, trained in explicit mirror-image discrimination of visuospatial patterns, have as good mirror-image discrimination as exilliterate adults (and better than illiterate who are not lace-makers: Kolinsky \& Verhaeghe, 2017). Moreover, congenital-blind readers of Braille (a tactile script with more mirrored graphs than Latin alphabet) have as good explicit mirror-image discrimination as Latin-alphabet readers and both groups show mirror costs (de Heering et al., 2018).

Our findings suggest that the importance of explicit training in mirror-image discrimination (e.g., via learning to read in a script with mirrored graphs) is contingent on mirror images becoming graphemically contrastive, i.e., both are real graphs associated with different meanings (de Heering \& Kolinsky, 2019). The fact that in Tamil monoliterate adults, who were able to explicitly discriminate mirror images, no mirror cost was found even with Latin-alphabet letters demonstrates that the strongest force for breaking mirror invariance is learning a script with mirrored graphs.

\section{Supplemental material}

Material, E-Prime programs, and data are publicly available at htt ps://osf.io/byqwj/ (DOI: 10.17605/OSF.IO/BYQWJ).([dataset] Fernandes, Arunkumar, \& Huettig, 2019).

\section{Author contribution}

T. Fernandes and F. Huettig conceptualized the study. T. Fernandes designed and developed the study. M. Arunkumar recruited the participants and collected data. T. Fernandes conducted all analyses and curated the data. All authors contributed to interpretation and discussion of the results. T. Fernandes and F. Huettig drafted a first version of the manuscript, critically revised it, and prepared the revised versions of the manucript. All authors approved the final versions submitted and revised for publication.

\section{Declaration of Competing Interest}

None.

\section{Acknowledgments}

This work was supported by Fundação para a Ciência e Tecnologia, FCT, and FEDER (POR Lisboa 2020; Project VOrtEx, PTDC/PSI-GER/ 28184/2017), the Research Center for Psychological Science (CICPSI) at Universidade de Lisboa, and by the Max Planck Society.

We thank the assistance of the NGO ARUWE in participants' recruitment.

Financial sources had no involvement in this research.

\section{Appendix A. Supplementary data}

Supplementary data to this article can be found online at https://doi. org/10.1016/j.cognition.2020.104493.

\section{References}

JASP, Team. (2019). JASP (version 0.10). Retrieved from https://jasp-stats.org/.

Ahr, E., Houdé, O., \& Borst, G. (2016). Inhibition of the mirror generalization process in reading in school-aged children. Journal of Experimental Child Psychology, 145, 157-165. https://doi.org/10.1016/j.jecp.2015.12.009.

Bigsby, P. (1988). The visual processor module and normal adult readers. British Journal of Psychology, 79(4), 455.

Boles, D. B. (1986). Confusion and visual field effects in rhyme and name letter matching. Perception \& Psychophysics, 39(2), 123-128. https://doi.org/10.3758/bf03211494.

Bornstein, M. H., Gross, C. G., \& Wolf, J. Z. (1978). Perceptual similarity of mirror images in infancy. Cognition, 6, 89-116. https://doi.org/10.1016/0010-0277(78)90017-3.
Carrasco, M., Kinchla, R. A., \& Figueroa, J. G. (1988). Visual letter-matching and the time course of visual and acoustic codes. Acta Psychologica, 69(1), 1-17.

Carreiras, M., Seghier, M. L., Baquero, S., Estevez, A., Lozano, A., Devlin, J. T., \& Price, C. J. (2009). An anatomical signature for literacy. Nature, 461(7266), 983-986. https://doi.org/10.1038/nature08461.

Chang, L. Y., Chen, Y. C., \& Perfetti, C. A. (2018). GraphCom: A multidimensional measure of graphic complexity applied to 131 written languages. Behavior Research Methods, 50(1), 427-449. https://doi.org/10.3758/s13428-017-0881-y.

Corballis, M. C. (2018). Mirror-image equivalence and Interhemispheric Mirror-image reversal. Frontiers in Human Neuroscience, 12, 140. https://doi.org/10.3389/ fnhum.2018.00140.

Danziger, E., \& Pederson, E. (1998). Through the looking-glass: Literacy, writing systems and mirror-image discrimination. Written Language and Literacy, 1(2), 153-164. https://doi.org/10.1075/wll.1.2.02dan.

Dehaene, S., Cohen, L., Morais, J., \& Kolinsky, R. (2015). Illiterate to literate: Behavioural and cerebral changes induced by reading acquisition. Nature Reviews Neuroscience, 16(4), 234-244. https://doi.org/10.1038/nrn3924.

Dehaene, S., Nakamura, K., Jobert, A., Kuroki, C., Ogawa, S., \& Cohen, L. (2010). Why do children make mirror errors in reading? Neural correlates of mirror invariance in the visual word form area. Neuroimage, 49, 1837-1848. https://doi.org/10.1016/j. neuroimage.2009.09.024.

Dehaene, S., Pegado, F., Braga, L. W., Ventura, P., Nunes, G., Jobert, A., ... Cohen, L. (2010). How learning to read changes the cortical networks for vision and language. Science, 330, 1359-1364. https://doi.org/10.1126/science.1194140.

Dehaene-Lambertz, G., Monzalvo, K., \& Dehaene, S. (2018). The emergence of the visual word form: Longitudinal evolution of category-specific ventral visual areas during reading acquisition. PLoS Biology, 16(3), Article e2004103. https://doi.org/ 10.1371/journal.pbio.2004103.

Duñabeitia, J. A., Molinaro, N., \& Carreiras, M. (2011). Through the looking-glass: Mirror reading. Neuroimage, 54, 3004-3009. https://doi.org/10.1016/j. neuroimage.2010.10.079.

Fernandes, T., Arunkumar, M., \& Huettig, F. (2019). Mirror-image discrimination in Tamil. OSF. https://doi.org/10.17605/OSF.IO/BYOWJ (dataset).

Fernandes, T., Coelho, B., Lima, F., \& Castro, S. L. (2018). The handle of literacy: Evidence from preliterate children and illiterate adults on orientation discrimination of graspable and non-graspable objects. Language, Cognition and Neuroscience, 33(3), 1-15. https://doi.org/10.1080/23273798.2017.1283424.

Fernandes, T., \& Kolinsky, R. (2013). From hand to eye: The role of literacy, familiarity, graspability, and vision-for-action on enantiomorphy. Acta Psychologica, 142, 51-61. https://doi.org/10.1016/j.actpsy.2012.11.008.

Fernandes, T., \& Leite, I. (2017). Mirrors are hard to break: A critical review and behavioral evidence on mirror-image processing in developmental dyslexia. Journal of Experimental Child Psychology, 159, 66-82. https://doi.org/10.1016/j. jecp.2017.02.003.

Fernandes, T., Leite, I., \& Kolinsky, R. (2016). Into the looking glass: Literacy acquisition and mirror invariance in preschool and first-grade children. Child Development, 87 (6), 2008-2025. https://doi.org/10.1111/cdev.12550.

Fischer, J. P. (2017). Character reversal in children: The prominent role of writing direction. Reading and Writing, 30(3), 523-542. https://doi.org/10.1007/s11145016-9688-y.

Gibson, E. J., Pick, A. D., Osser, H., \& Gibson, J. J. (1962). A developmental study of discrimination of letter-like forms. Journal of Comparative and Physiological Psychology, 55, 897-906. https://doi.org/10.1037/h0043190.

Hannagan, T., Amedi, A., Cohen, L., Dehaene-Lambertz, G., \& Dehaene, S. (2015) Origins of the specialization for letters and numbers in ventral occipitotemporal cortex. Trends in Cognitive Sciences, 19, 374-382. https://doi.org/10.1016/j. tics.2015.05.006.

de Heering, A., Collignon, O., \& Kolinsky, R. (2018). Blind readers break mirror invariance as sighted do. Cortex, 101, 154-162. https://doi.org/10.1016/j. cortex.2018.01.002.

de Heering, A., \& Kolinsky, R. (2019). Braille readers break mirror invariance for both visual braille and Latin letters. Cognition, 189, 55-59. https://doi.org/10.1016/j. cognition.2019.03.012.

Hervais-Adelman, A., Uttam, K., Mishra Ramesh, K., Tripathi Viveka, N., Anupam, G., Singh Jay, P., ... Falk, H. (2019). Learning to read recycles visual cortical networks without destruction. Science Advances, 5(9), eaax0262. https://doi.org/10.1126/ sciadv.aax0262.

Jeffreys, H. (1961). Theory of probability (3rd ed.). Oxford, UK: Oxford University Press.

Kolinsky, R., \& Fernandes, T. (2014). A cultural side effect: Learning to read interferes with identity processing of familiar objects. Frontiers in Psychology, 5, 1224. https:// doi.org/10.3389/fpsyg.2014.01224. Research Topic: The impact of learning to read on visual processing.

Kolinsky, R., Morais, J., \& Brito-Mendes, C. (1990). Embeddedness effects on part verification in children and unschooled adults (Vol. 30, pp. 49-64). Belgium: Belgian Association for Psychological Science.

Kolinsky, R., Morais, J., Content, A., \& Cary, L. (1987). Finding parts within figures: A developmental study. Perception, 16(3), 399-407.

Kolinsky, R., \& Verhaeghe, A. (2017). Lace your mind: The impact of an extra-curricular activity on enantiomorphy. Journal of Cultural Cognitive Science, 1(2), 57-64. https:// doi.org/10.1007/s41809-017-0007-1.

Kolinsky, R., Verhaeghe, A., Fernandes, T., Mengarda, E. J., Grimm-Cabral, L., \& Morais, J. (2011). Enantiomorphy through the looking glass: Literacy effects on mirror-image discrimination. Journal of Experimental Psychology: General, 140 , 210-238. https://doi.org/10.1037/A0022168. 
Lachmann, T., \& van Leeuwen, C. (2008). Different letter-processing strategies in diagnostic subgroups of developmental dyslexia. Cognitive Neuropsychology, 25(5), 730-744. https://doi.org/10.1080/02643290802309514.

Lachmann, T., \& van Leeuwen, C. (2014). Reading as functional coordination: Not recycling but a novel synthesis. Frontiers in Psychology, 5. https://doi.org/10.3389/ fpsyg.2014.01046.

Logothetis, N. K., Pauls, J., \& Poggio, T. (1995). Shape representation in the inferior temporal cortex of monkeys. Current Biology, 5(5), 552-563.

Longcamp, M., Boucard, C., Gilhodes, J. C., Anton, J. L., Roth, M., Nazarian, B., \& Velay, J. L. (2008). Learning through hand- or typewriting influences visual recognition of new graphic shapes: Behavioral and functional imaging evidence. Journal of Cognitive Neuroscience, 20(5), 802-815. https://doi.org/10.1162/ jocn.2008.20504.

Macmillan, N. A., \& Creelman, C. D. (2005). Detection theory: A user's guide (2nd ed.). Mahwah, NJ: Erlbaum.

Martinaud, O., Mirlink, N., Bioux, S., Bliaux, E., Champmartin, C., Pouliquen, D., ... Gerardin, E. (2016). Mirrored and rotated stimuli are not the same: A neuropsychological and lesion mapping study. Cortex, 78, 100-114. https://doi.org/ 10.1016/j.cortex.2016.03.002.

Morin, O. (2018). Spontaneous emergence of legibility in writing systems: The case of orientation anisotropy. Cognitive Science, 42(2), 664-677. https://doi.org/10.1111/ cogs. 12550.

Nag, S., \& Narayanan, B. (2019). Orthographic knowledge, reading and spelling development in Tamil: The first three years. In R. Malatesha Joshi, \& C. McBride (Eds.), Handbook of Literacy in Akshara Orthography (pp. 55-83). Springer International Publishing ed. (Cham).
Pederson, E. (2003). Mirror-image discrimination among nonliterate, monoliterate, and biliterate Tamil subjects. Written Language and Literacy, 6, 71-91. https://doi.org/ 10.1075/wll.6.1.04ped.

Pegado, F., Nakamura, K., Braga, L. W., Ventura, P., Filho, G. N., Pallier, C., ... Dehaene, S. (2014). Literacy breaks mirror invariance for visual stimuli: A behavioral study with adult illiterates. Journal of Experimental Psychology: General, 143, 887-894. https://doi.org/10.1037/a0033198.

Pegado, F., Nakamura, K., Cohen, L., \& Dehaene, S. (2011). Breaking the symmetry: Mirror discrimination for single letters but not for pictures in the visual word form area. Neuroimage, 55, 742-749. https://doi.org/10.1016/j.neuroimage.2010.11.043.

Pegado, F., Nakamura, K., \& Hannagan, T. (2014). How does literacy break mirror invariance in the visual system? Frontiers in Psychology, 5. https://doi.org/10.3389/ fpsyg.2014.00703.

Perea, M., Moret-Tatay, C., \& Panadero, V. (2011). Suppression of mirror generalization for reversible letters: Evidence from masked priming. Journal of Memory and Language, 65(3), 237-246. https://doi.org/10.1016/j.jml.2011.04.005.

Ramanujan, K., \& Weekes, B. S. (2019). What Is an Akshara? In R. Malatesha Joshi, \& C. McBride (Eds.), Handbook of literacy in Akshara orthography (pp. 43-52). Cham: Springer International Publishing.

Steever, S. B. (1996). Tamil writing. In P. T. Daniels, \& W. Bright (Eds.), The world's writing systems (pp. 426-430). New York, USA: Oxford University Press.

Treiman, R., Gordon, J., Boada, R., Peterson, R. L., \& Pennington, B. F. (2014). Statistical learning, letter reversals, and Reading. Scientific Studies of Reading, 18(6), 383-394. https://doi.org/10.1080/10888438.2013.873937.

Wagenmakers, E.-J., Love, J., Marsman, M., Jamil, T., Ly, A., Verhagen, J., .. Morey, R. D. (2018). Bayesian inference for psychology. Part II: Example applications with JASP. Psychonomic Bulletin \& Review, 25(1), 58-76. https://doi. org/10.3758/s13423-017-1323-7. 